\title{
Tranexamic Acid for Prevention of Postpartum Hemorrhage after Vaginal Delivery
}

\author{
Esmail Talaat El-Garhy and Ashraf Hamdy Mohamed ,Ashraf Elshahat ,Ibrahim Abu \\ Elmagd ,Mohamed Awad Allah Hamed* \\ Department of Obstetrics and Gynaecology, Faculty of Medicine, Al-Azhar University, Cairo, Egypt. \\ *Corresponding author: Mohamed Awad ALLAH Hamed, E-mail : moda6366@gmail.com
}

\begin{abstract}
:
Objective: To assess the efficacy of tranexamic acid in reduction of blood loss and pervention of postpartum hemorrhage after vaginal delivary. Methods: This is a multicentric prospective randomized double blind placebo controlled trial. 200 pregnant women were randomized to receive either $60 \mathrm{mg} / \mathrm{kg}$ of tranexamic acid (TA) $(n=100)$ or placebo $(n=100)$ intravenously in the second stage of labour. Postpartum blood loss was collected and measured accurately from placental delivery to 2 hours postpartum and adverse effects of were observed. Results: The mean estimated postpartum blood loss was significantly lower in women treated with tranexamic acid compared to women in the placebo group ( $442.50 \pm 128.55$ versus 555.75 \pm 191.88 , respectively; $\mathrm{p}<0.001$ ), and the proportion of women in the tranexamic acid group who had an estimated blood loss $\geq 500 \mathrm{~mL}$ was significantly lower than in the placebo group( $3\left[\begin{array}{ll}3 & \%\end{array}\right]$ versus $9 \quad[9 \%]$,relative risk $[\mathrm{RR}]=0.30 ; \quad 97 \%$ confidence interval $[\mathrm{CI}] \quad 0.11$ to $0.78 ; \mathrm{P}<0.05)$. Maternal and neonatal outcomes did not differ significantly between both groups. Conclusion: The addition of tranexamic acid to the active management of third stage of labor after normal vaginal delivery is effective as a prophylaxis against post-partum hemorrhage. It can significantly reduce blood loss during and after delivery.
\end{abstract}

Keywords: Tranexamic acid, postpartum haemorrhage, Blood loss

\section{Introduction}

Postpartum haemorrhage (PPH) stills the most common cause of maternal mortality worldwide, accounting for about 300,000 deaths every year, and most of deaths occur in the immediate postpartum period [1] $\mathrm{PPH}$ causes morbidity related to anaemia, blood transfusion and haemorrhage related ischaemic complications. Haemostatic abnormalities have long been considered consequences of uncontrolled bleeding. PPH also contributes to hospital morbidity because patients may require a blood transfusion, which can transmit blood borne viral infections. Approximately $1 \%$ of women with spontaneous vaginal deliveries receive a blood transfusion, but the rate increases to about $5 \%$ for women with instrumental deliveries or caesarean sections $^{[2]}$.Direct causes of PPH are mainly uterine atony, trauma to the birth canal, coagulopathy and retained placenta ${ }^{[3]}$. PPH is poorly predictable, underestimated when diagnosed clinically and not deserving of early specific treatment. Accordingly, detailed guidelines have been issued for optimal use of obstetric interventions and uterotonic drugs.

PPH is commonly defined as blood loss of $\geq 500 \mathrm{ml}$ after vaginal delivery of a baby, or $\geq 1000 \mathrm{ml}$ after caesarean section. However, these thresholds do not take into account pre-existing health status, and blood loss of as little as $200 \mathrm{~mL}$ can be lifethreatening for a woman with severe anaemia or cardiac disease and the problem is more hazardous in the developing countries $^{[4]}$. Therefore, measures aiming to reduce postpartum blood loss have positive effects in reducing bleeding related maternal morbidity and contributing the global commitment to the Millennium Development Goal (MDG) of reducing maternal deaths by three-quarters by the year 2015, a commitment that requires a reduction 
of the maternal mortality ratio by $5.5 \%$ each year. Several measures for minimizing bleeding as well as preventing $\mathrm{PPH}$ are available, but further advances in this field are important, especially the identification of safe, easy to use, and cost-effective regimes. Tranexamic acid (TA) merits evaluation to assess whether it meets these criteria. TA was chosen because it has been demonstrated to bea potent antifibrinolytic agent in elective surgical patients and because it is the most often used antifibrinolytic agent worldwide. TA has the additional advantages of being inexpensive and easy to stock and handle.

TAis a synthetic derivative of the amino acid lysine that exerts its antifibrinolytic effect through the reversible blockade of the lysine binding sites on plasminogen molecules and has the potential to enhance the effectiveness of the patient's own haemostatic mechanisms. Consequently, clot breakdown(fibrinolysis) is inhibited and excessive or recurrent bleeding is reduced ${ }^{[5]}$. Intravenous administration of TA has been routinely used for many years to reduce hemorrhage during and after surgical procedures like coronary artery bypass, oral surgery, orthopedic surgery, liver transplantation and urinary tract surgery. TA has been shown to be very useful in reducing blood loss and incidence of blood transfusion in these surgeries ${ }^{[6]}$. Moreover, the Clinical Randomization of an Antifibrinolytic in Significant Haemorrhage (CRASH-2) study demonstrated that TA safely reduces the risk of death in bleeding trauma patients $^{[7]}$.

TA significantly reduces uterine blood loss in women with menorrhagia and is recommended for consideration as a treatment in intractable postpartum haemorrhage. In the field of obstetrics, four randomized controlled trials have shown that TA reduces postpartum bleeding following cesarean delivery but only one randomized trial is available evaluating the effect of TA use to prevent bleeding in the postpartum period following spontaneous vaginal delivery. However, quality of these trials was poor. None had adequate allocation concealment and trials were too small to assess the effect of TA and none used a large dose of intravenous TA. Many non-obstetric trials have been proved the safety of high doses of TA. Freeman et al. ${ }^{[8]}$ reported that doubling daily dose of TA is associated with a significant reduction of blood loss among women with heavy menstrual beeding without increase in adverse effects of TA. Ducloy-Bouthors et al. [9] were the first to study the high dose of intravenous TA in obstetric field and reported that it can reduce blood loss and maternal morbidity in women with established PPH and strongly supported the need for large study to investigate the potential of high dose of TA to reduce maternal morbidity worldwide.

In a delivery room, a patient was placed in the lithotomy position with a graduated collector bag directly underneath it , and the delivery equipment nearby. This collector bag is used routinely by our caregivers to estimate blood loss after each vaginal delivery in the lithotomy position, which is the current standard position for vaginal deliveries. The collector bag is a plastic collector bag graduated every $100 \mathrm{ml}$ from zero $\mathrm{ml}$ to $1500 \mathrm{ml}$. Each volume was to be analyzed separately by each individual participant. There were three volumes to be analyzed: $350 \mathrm{ml}, \quad 1100 \mathrm{ml}$ and $2500 \mathrm{ml}$. This method was designed for participants to assume that the collector bag contained only blood, and that the fluid on the obstetrical equipment nearby was also blood. According to the method, blood loss was contained in the collector bag but also on obstetrics materials such as a kidney dish, hospital sheets, incontinence 
pad, and sanitary towel. All of the equipment's weight (prior to the addition of blood) was known and presented on an accessible table in the same room where the delivery occurred (sanitary towel, incontinence pad, hospital sheets and kidney dish). A baby weight scale was set up on the side to be used by participants if they wanted to weigh the obstetrical materials covered in blood for estimating the three different volumes ${ }^{[10]}$.

This study aims to assess the efficacy of addition of Tranexmic Acid (TXA) to the active management of the third stage of labor (AMTSL) in reducing the amount of blood loss during normal vaginal delivery.

\section{Methods}

This randomized double blinded prospective case control trial was conducted at Damietta General Hospital in the period of 3rd of July 2017 till 25th of December 2017. The study was approved by the Ethics Board of Al-Azhar University.

Randomization was done by the rule of odds and even. 200 pregnant women were enrolled in the study. In 100 women, tranexamic acid (kapron ampoule $\quad\left[\begin{array}{llll}500 & \mathrm{mg} / 5 & \mathrm{ml}\end{array}\right]$ manufactured by Amoun, Eygpt) was given before vaginal delivery (TA group) compared with that in 100 others to whom saline solution (sodium chloride 0.9\%) was given (control group). Full term pregnant women (gestational age $\geq 37$ weeks) with singleton pregnancy being delivered vaginally were included in the study. Exclusion criteria were age $<18$ years, women delivered by caesarean section, presence of known haemostatic abnormalities, history of thrombosis or epilepsy, history of medical problems involving the heart, liver, kidney and brain. Women with known allergy to tranexamic acid, abnormal placentation, antepartum haemorrhage, uterine scar, severe preeclampsia, multiple pregnancy, macrosomia, polyhydromnios, women taking anticoagulant drugs and those requiring blood transfusion due to severe anemia were also excluded from the study. All women were given information about the study and written consent was taken from each of them.

In TA group,tranexamic acid in dose of $60 \mathrm{mg} / \mathrm{kg}$ was given slowly intravenously over 5 minutes $/ 500 \mathrm{mg}$ $(5 \mathrm{ml})$. In control group, saline solution was given slowly intravenously by corresponding volume and duration according to maternal body weight. Intravenous TA administration was started in the second stage of labour in both groups. Immediately after delivery of the fetal shoulders, 10 units of oxytocin in $500 \mathrm{ml}$ of dextrose $5 \%$ was given by intravenous drip over 30 minutes and $0.4 \mathrm{mg}$ methyl ergometrine was given intravenously and this was applied for all women in both groups. In each participating Centre, an under-buttock splastic drape draining blood in graduated metal container used in delivery room and another under-buttocks plastic drape with a collection pouch was placed after each vaginal delivery in postnatal room to measure blood loss in the postpartum period. Over estimation of blood loss because of the addition of antiseptic or saline solutions used for sterilization or washing during delivery was avoided. Midwives unaware of the group allocation measured the volume of blood in the metal container and collection pouches of drapes. Soaked mops, gauzes, pads, drapes and bed sheets were weighed by electronic scale (with $1 \mathrm{~g}$ deviation range) before and after blood soaking. Hemoglobin \%, urine analysis, liver and renal function were noted before delivery and on the postnatal visits one week after delivery. Major side effects of TA (such as thrombotic events, renal failure or seizures) and minor side effects were reported during postnatal visits. With respect to venous thrombosis, clinical signs of 
superficial or deep thrombosis were collected, and ultrasonography was performed as soon as the signs were detected. Outcome measures of interest were the amount of blood loss, number of women lost more than $500 \mathrm{ml}$ of blood from placental delivery to 2 hours postpartum and adverse effect of TA therapy.

\section{Statistical analysis:}

Collected data were expressed as means \pm SD in cases of normal distribution and as medians and interquartile ranges otherwise. Comparisons between groups were performed using the X2 test or Fisher's exact test for categorical variables. For numerical variables, we used Student's t-test in cases of normal distribution and the MannWhitney $U$ test otherwise. All statistical analyses were performed using SAS software (SAS Institute, Cary, NC, USA). $\mathrm{P}$ value< 0.05 was considered statistically significant.

\section{Results}

There is no statistical significant difference between TA group $(\mathrm{n}=100)$ and control group $(\mathrm{n}=100)$ regarding maternal and obstetric characteristics including maternal

Table (1): Comparison between the and obstetric characteristics age, weight, height, gestational age, parity, duration of the second stage of labour and instrumental delivery $(\mathrm{P}>0.05$, table 1). The median volume of postpartum blood loss from placental delivery to 2 hours postpartum, were significantly lower in the TA group than control group $(241.5 \pm 82.7$ versus $322.8 \pm 127.4$, $\mathrm{P}<0.001$; table 2).

According to World Health Organization (WHO) definition of postpartum haemorrhage (PPH) as a loss of $\geq 500 \mathrm{ml}$ of blood after placental delivery [18], there was significant reduction in incidence of $\mathrm{PPH}$ in TA group compared to control group ( 3 [3\%]versus 9 $[9 \%] \%$,relative risk $[\mathrm{RR}]=0.30 ; \quad 97 \%$ confidence interval [CI] 0.11 to $0.78 ; \mathrm{P}<0.05 ;$ table 2).As regard side effects of treatment, there were no significant differences between both groups regarding severe or nonsevere complications of TA. There were no fetal or maternal deaths. There were no significant differences in either Apgar scores at 1 and 5 minutes or neonatal intensive care admission between both groups $(\mathrm{P}>0.05$, table4).

studied groups according to Maternal

\begin{tabular}{|c|c|c|c|c|}
\hline & $\begin{array}{l}\text { Study } \\
(n=100)\end{array}$ & $\begin{array}{l}\text { Control } \\
(n=100)\end{array}$ & MW & $\mathbf{P}$ \\
\hline $\begin{array}{l}\text { Age (years) } \\
\text { Min. - Max. } \\
\text { Mean } \pm \text { SD. } \\
\text { Median }\end{array}$ & $\begin{array}{l}20.0-38.0 \\
29.03 \pm 4.51 \\
29.0\end{array}$ & $\begin{array}{l}20.0-38.0 \\
28.08 \pm 4.81 \\
27.0\end{array}$ & 1.287 & 0.200 \\
\hline $\begin{array}{l}\text { Gestational a } \\
\text { Min. - Max. } \\
\text { Mean } \pm \text { SD. } \\
\text { Median }\end{array}$ & $\begin{array}{l}37.0-40.0 \\
38.67 \pm 0.96 \\
39.0\end{array}$ & $\begin{array}{l}37.0-40.0 \\
38.36 \pm 0.93 \\
38.0\end{array}$ & $1.983^{*}$ & 0.447 \\
\hline $\begin{array}{l}\text { BMI }(\mathbf{k g} / \mathbf{m} 2) \\
\text { Min. - Max. } \\
\text { Mean } \pm \text { SD. } \\
\text { Median }\end{array}$ & $\begin{array}{l}25.39-40.09 \\
32.88 \pm 2.76 \\
32.67\end{array}$ & $\begin{array}{l}28.28-42.24 \\
33.59 \pm 3.22 \\
33.39\end{array}$ & 1.489 & 0.138 \\
\hline $\begin{array}{l}\text { Gravidity } \\
\text { Min. - Max. } \\
\text { Mean } \pm \text { SD. } \\
\text { Median } \\
\end{array}$ & $\begin{array}{l}1.0-5.0 \\
3.35 \pm 0.97 \\
3.0\end{array}$ & $\begin{array}{l}2.0-6.0 \\
3.28 \pm 1.06 \\
3.0\end{array}$ & 0.926 & 0.354 \\
\hline $\begin{array}{l}\text { Parity } \\
\text { Min. - Max. } \\
\text { Mean } \pm \text { SD. } \\
\text { Median }\end{array}$ & $\begin{array}{l}0.0-3.0 \\
1.75 \pm 0.77 \\
2.0\end{array}$ & $\begin{array}{l}1.0-4.0 \\
1.68 \pm 0.82 \\
1.0\end{array}$ & 1.010 & 0.312 \\
\hline $\begin{array}{l}\text { Abortion } \\
\text { Min. - Max. } \\
\text { Mean } \pm \text { SD. } \\
\text { Median }\end{array}$ & $\begin{array}{l}0.0-2.0 \\
0.60 \pm 0.63 \\
1.0\end{array}$ & $\begin{array}{l}0.0-2.0 \\
0.60 \pm 0.67 \\
0.50\end{array}$ & 0.122 & 0.903 \\
\hline
\end{tabular}


Esmail El-Garhy et al.

Table (2):Comparison between the two studied groups according to amount of blood loss.

\begin{tabular}{|c|c|c|c|c|}
\hline Blood loss & $\begin{array}{l}\begin{array}{l}\text { Study } \\
(n=100)\end{array} \\
\end{array}$ & $\begin{array}{l}\text { Control } \\
\mathbf{n}=100)\end{array}$ & MW & $\mathbf{P}$ \\
\hline $\begin{array}{l}\text { During delivery } \\
\text { Min. - Max. } \\
\text { Mean } \pm \text { SD. } \\
\text { Median } \\
\end{array}$ & $\begin{array}{l}250.0-650.0 \\
351.25 \pm 111.09 \\
350.0\end{array}$ & $\begin{array}{l}250.0-900.0 \\
456.25 \pm 169.95 \\
400.0\end{array}$ & $4.354^{*}$ & $<0.001^{*}$ \\
\hline $\begin{array}{l}\mathbf{2 4} \text { hour } \\
\text { delivery } \\
\text { Min. - Max. } \\
\text { Mean } \pm \text { SD. } \\
\text { Median }\end{array}$ & $\begin{array}{l}80.0-140.0 \\
91.25 \pm 17.46 \\
80.0\end{array}$ & $\begin{array}{l}80.0-140.0 \\
99.50 \pm 21.93 \\
95.0\end{array}$ & $2.480^{*}$ & $0.013^{*}$ \\
\hline $\mathbf{p}_{1}$ & $<0.001^{*}$ & $<0.001^{*}$ & & \\
\hline $\begin{array}{l}\text { Total blood loss } \\
\text { Min. - Max. } \\
\text { Mean } \pm \text { SD. } \\
\text { Median }\end{array}$ & $\begin{array}{l}330.0-790.0 \\
442.50 \pm 128.55 \\
430.0\end{array}$ & $\begin{array}{l}330.0-1040.0 \\
555.75 \pm 191.88 \\
480.0\end{array}$ & $4.287^{*}$ & $<0.001^{*}$ \\
\hline
\end{tabular}

Table (3):Comparison between the two studied groups according to incidence of PPH.

\begin{tabular}{|l|l|l|l||}
\hline & $\begin{array}{l}\text { Study group } \\
(\mathbf{n}=100)\end{array}$ & $\begin{array}{l}\text { Control group } \\
(\mathbf{n}=100)\end{array}$ & P value \\
\hline Incidence of PPH & $\mathbf{3 ( 3 \% )}$ & $\mathbf{9}(\mathbf{9 \%})$ & $<0.001$ \\
\hline
\end{tabular}

$\mathbf{P P}=$ postpartum $\mathbf{P P H}=$ postpartum haemorrhge

Table (4):Comparison between the two studied groups according to side effect of treatment.

\begin{tabular}{|c|c|c|c|}
\hline Side effect & $\begin{array}{l}\text { Study group } \\
\mathbf{n},(\%)\end{array}$ & $\begin{array}{l}\text { Control group } \\
\mathbf{n},(\%)\end{array}$ & P value \\
\hline $\begin{array}{l}\text { Non severe side effects } \\
\text { Nausea/vomiting } \\
\text { Headache } \\
\text { Dizziness } \\
\text { Allergic reactions } \\
\text { Severe side effects } \\
\text { DVT } \\
\text { Renal impairment } \\
\text { Liver impairment } \\
\text { Seizures } \\
\text { Maternal death } \\
\text { Neonatal death intensive } \\
\text { Neonatal care } \\
\text { admission }\end{array}$ & $\begin{array}{l}8(8 \%) \\
7(7 \%) \\
6(6 \%) \\
0(0) \\
0(0) \\
0(0) \\
0(0) \\
0(0) \\
0(0) \\
0(0) \\
4(4 \%)\end{array}$ & $\begin{array}{l}6(6 \%) \\
4(4 \%) \\
5(5 \%) \\
0(0) \\
0(0) \\
0(0) \\
0(0) \\
0(0) \\
0(0) \\
0(0) \\
5(5 \%)\end{array}$ & $\begin{array}{l}\text { NS } \\
\text { NS } \\
\text { NS } \\
\text { NS } \\
\text { NS } \\
\text { NS } \\
\text { NS } \\
\text { NS } \\
\text { NS } \\
\text { NS } \\
\text { NS }\end{array}$ \\
\hline
\end{tabular}

DVT=deep venous thrombosis \&Renal and liver impairment= abnormal renal and liver functions

\section{Discussion}

In this study, there was no significant difference as regard patient demographic data (age, weight, BMI, parity and gestational age) between study and control groups.

The number of cases with PPH was highly significant lower in study group ( 3 cases) than control group (9 cases) $(\mathrm{p}<0.001)$.
The total amount of blood loss from placental separation until end of delivery was highly significant lower in study group than control group by $(128.5 \pm 26.9 \mathrm{ml})(\mathrm{p}<0.001)$.

Tranexmic Acid significantly reduced bleeding during labor. The total blood loss from placental delivery till 24 hours postpartum in study group $:(442.50 \pm 128.55 \mathrm{ml})$ was significantly less than control 
group $(555.75 \pm 191.88 \mathrm{ml})$. The difference in blood loss equals to $(113.25+63.33 \mathrm{ml})$.

In the current study the amount of blood loss during and after delivery was significantly increased in the control group compared to the study group, comparison between the study group and the control group as regards the total amount of blood loss showed that the study group total blood loss ranged from 330.0 to 790.0 with mean \pm SD was $442.50 \pm$ 128.55, while the control group total blood loss ranged from 330.0 to $1040.0 \mathrm{~mL}$ with mean $\pm \mathrm{SD}$ was $555.75 \pm$ 191.88. Denoting the tranexamic acid significantly reduces bleeding during and after delivery.

In the current study the hemoglobin and hematocrit (Hct) pre-delivery levels were similar but after delivery the comparison between the two groups as regarding the hemoglobin level after delivery showed that the change in $\mathrm{Hb}$ level in the study group ranged from $10.08 \pm 1.78 \%$, while the change in the $\mathrm{Hb}$ level in the control group ranged from $14.28 \pm$ $1.76 \%$.There was a significant decrease in hemoglobin level in the control group. As regarding the hematocrit level after delivery the comparison between the two groups showed that the change in Hct level in the study ranged from $7.68 \pm 2.07$ $\%$, while the change in the Hct level in the control group ranged from $11.40 \pm 3.26 \%$. There was a significant decrease in hematocrit level in the control group.

This study showed that tranexamic acid significantly reduces blood loss from time of placental delivery to 2 hours postpartum after vaginal delivery $\quad(\mathrm{P}<0.001)$. This study also showed a significant decrease in the incidence of $\geq 500 \mathrm{~mL}$ blood loss in TA group compared to control group $(\mathrm{P}<0.01)$. Results of our study have been corroborated by the four trials those investigated the effect of TA injection before caesarean deliveries $^{[11]}$ and the only one trial carried out by Yang et al. $^{[12]}$ that investigated the efficacy of TA in reducing postpartum bleeding after spontaneous vaginal delivery. However, the incidence of $\mathrm{PPH}$ in TA group compared to control group was lower in our study $(\mathrm{RR}=0.30)$ than reported by other trials. A pooled relative risk for 3 of these trials was 0.44 and $\mathrm{RR}$ reported by Gungorduk et $\mathrm{al}^{[13]}$ was 0.37 . This could be mostly explained by using a higher dose of TA in our trial than doses used in those trials.

Yang et al. reported no significant differences between women injected by $0.5 \mathrm{gm}$ TA and those injected by 1 gm TA before vaginal delivery regarding postpartum blood loss and incidence of PPH. However, Yang et al compared two relatively small fixed doses of TA $(0.5 \mathrm{gm}$ and $1 \mathrm{gm})$ irrespective to maternal body weight that might expose the trial to risk of bias. They also used $400 \mathrm{ml}$ instead of $500 \mathrm{ml}$ as a threshold of blood loss in diagnosis of $\mathrm{PPH}$, studied lower samples (less than 100 women in each group), excluded instrumental deliveries, multigravidas and adopted inadequate allocation concealment. No other studies compared the different doses of TA in obstetrics. However, Ducloy-Bouthors et al. reported that high-dose of TA (loading dose $4 \mathrm{~g}$ over 1 hour, then infusion of 1 g/hour over 6 hours) can reduce blood loss and maternal morbidity in women with PPH. Given the lack of previous obstetric studies on the efficacy of higher doses of TA, we chosed TA (60 $\mathrm{mg} / \mathrm{kg}$ ) in our study as the best clinically effective dose used to reduce haemorrhage in high-risk cardiac surgery patients ${ }^{[14]}$.

No single patient developed severe side effects such as thrombosis, allergic reaction, seizures, renal or hepatic impairment and incidences of non-severe side effects like nausea, vomiting and diarrhea as well as neonatal morbidity were not statistically significant by difference in the two groups. These have been corroborated by other non-obstetric 
studies that investigated adverse effects of high TA doses ${ }^{[15]}$. DucloyBouthors et al. reported 3 cases of deep venous thrombosis (DVT) but without significant differences between both groups (2cases in TA group [2.5\%] and 1 case in control group [1.3\%]; $\mathrm{P}=0.4$ ).

Because thromboembolic events are relatively rare, this trial lacks statistical power to detect the risk of thrombosis related to TA use in puerperium. As the risk of thromboembolism increased in pregnancy and the risk shows more increase in postpartum period,some increased risk of thromboembolic events with TA as a potent antifibrinolytic might be expected on theoretical grounds. Although, recent evidence from the CRASH-2 trial of TA in bleeding trauma patients showed a statistically significant reduction in mortality with no increase in thromboembolic effects, a need for a large pragmatic clinical trial of the effect of routine use of high dose TA on puerperal thromboembolic morbidity is warranted because a modest increase in the risk of thromboembolic morbidity could outweigh the benefits of reduced blood loss. A second limitation is that the design of this study was not powered to show decreases in maternal death. However, we demonstrated atrend toward a decrease in the rate of $\mathrm{PPH}$. From this perspective, we urge investigators involved inall ongoing trials of TA to collect data on thromboembolic events and mortality for inclusion in aprospective metaanalysis until these uncertainties are resolved. A third limitation of this study is that the duration of follow up was short and adverse events may have occurred after the study period ended. TA is not completely eliminated from the blood until 9-18 hours after administration . However, because the half-life of TA is two hours, levels in the blood would be reduced after the study period and any late adverse event would be discovered in postnatal visits.

Our results propose to future studies recommendations concerning to addition of tranexamic acid to the active management of third stage of labor after normal vaginal delivery is effective as a prophylaxis against post-partum hemorrhage as shown by the results of this study. It can significantly reduce blood loss during and after delivery. All data demonstrated that tranexamic acid can be used safely to reduce bleeding during and after vaginal delivery and its use was not associated with any maternal and neonatal side effects. Further trials that are placebo controlled are needed to observe for the occurrence of thrombosis. Further trials that include patients at higher risk of $\mathrm{PPH}$ might provide more evidence for the efficacy of tranexamic acid in reducing $\mathrm{PPH}$ as they were not included in this study. Further studies are needed to asses' possibility of use of tranexamic acid for treatment of intrapartum and postpartum hemorrhage.

Conclusion

The addition of tranexamic acid to the active management of third stage of labor after normal vaginal delivery is effective as a prophylaxis against post-partum hemorrhage as shown by the results of this study. It can significantly reduce blood loss during and after delivery. All data demonstrated that tranexamic acid can be used safely to reduce bleeding during and after vaginal delivery and its use was not associated with any maternal and neonatal side effect.

\section{References}

1. Hogan MC, Foreman KJ, Naghavi M, Ahn SY, Wang M, Makela SM, Lozano R, Murray CJ(2010): Maternal mortality for 181 countries,1980-2008: a systematic analysis of progress towards Millenium Development Goal 5. Lancet , 375:1609-1623.

2. Dupont C, Touzet S, Colin C, Deneux-Tharaux C, Rabilloud 
M, Clement HJ,Lansac J, Colle MH, Rudigoz RC, Groupe PITHAGORE 6(2009): Incidence and management of postpartum haemorrhage following the dissemination of guidelines in a network of 16 maternity units in France. Int $\mathbf{J}$ Obstet Anesth, 18(4):320-7.

3. Department of Reproductive Health and Research, World Health Organization(2009): WHO recommendations for the prevention of postpartum haemorrhage. Geneva, World Health

Organization,http://whqlibdoc.wh o.int/hq/2007/WHO_MPS_07.06_ eng.pdf

4. Lalonde Postpartum A et al.(2006): initiative2004-2006 Int J Gynaecol Obstet., 94(3):24353.

5. Ferrer P, Roberts I, Sydenham E, Blackhall K, Shakur H (2009): Anti-fibrinolytic agents in postpartum hemorrhage: a systematic review. BMC Pregnancy Childbirth, 9: 29.

6. Dunn PM and Goa KL (1999): Tranexamic acid:a review of its use in surgery and other indication. Drugs,57: 1005: 10032.

7. Shakur H, Roberts I, Bautista R, Caballero J, Coats $T$ et al.(2010): Effects of tranexamic acid on death, vascular occlusive events, and blood transfusion in trauma patients with significant hemorrhage (CRASH-2): a randomised, placebo-controlled trial. Lancet, 376:23-32.

8. Freeman EW, Lukes A, VanDrie D, Mabey RG, Gersten J, Adomako TL (2011):A doseresponse study of a novel, oral tranexamic formulation for heavy menstrual bleeding. Int $\mathrm{J}$ Obstet Gynecol. , 7(5):591-8.
9. Ducloy-Bouthors A, Jude B, Duhamel A et al.(2011): High dose tranexamic acid reduces blood loss in postpartum haemorrhge. Critical Care, 15:R117.

10. Zuckerwise $\mathrm{L}$ et al.(2014): Use of a novel visual aid to improve estimation of obstetric blood loss. Obstet Gynecol., 123(5): 982-6.

11. Gohel M, Patel P, Ashoo G, Desai $\quad \mathbf{P}(2007)$ Efficacy of tranexamic acid in decreasing blood loss during and after cesarean section: A randomised case controlled prospective study. J Gynaecol Obstet. India, 57(3):227-230.

12. Yang $\mathrm{H}$, Zheng $\mathrm{S}$, Shi $\mathrm{C}$ et al. (2001): Clinical study on the efficacy of tranexamic acid in reducing postpartum blood lose: a randomized, comparative, multicenter trial. Chin J Obstet gynecol.,6:590-592.

13. Gungorduk K, Yildirim G, Asicioglu $O$ et al. (2011): Efficacy of intravenous tranexamic acid in reducing blood loss after elective caesarean section; a prospective, randomized, double-blind, placebo- controlled study. Am J Perinataol., 28:233-240.

14. Karski JM, Dowd NP, Joiner R, Carroll J, Peniston C, Bailey K, Glynn MF, Teasdale SJ, Cheng DC(1998): The effect of three different doses of tranexamic acid on blood loss after cardiac surgery with mild systemic hypothermia (32 degrees C). J Cardiothorac Vasc Anesth., 12:642-646.

15. Heit JA et al.(2005): Trends in the incidence of venous thromboembolism during pregnancy or postpartum: a 30year population-based study.Ann Intern Med., 143(10):697-706. 